
Paper for the PSE special issue "Sport psychology and the Olympic Games"

Birrer, Daniel

Wetzel, Joerg

7

Schmid, Juerg

8

Morgan, Gareth

9

10

11 Analysis of sport psychology consultancy at three Olympic Games: Facts and figures

12

13 
Abstract

Objectives: Despite many reports on best practises regarding onsite psychological services, little research has attempted to systematically explore the frequency, issues, nature and client groups of onsite sport psychology consultancy at the Olympic Games. The present paper will fill this gap through a systematic analysis of the sport psychology consultancy of the Swiss team for the Olympic Games of 2006 in Turin, 2008 in Beijing and 2010 in Vancouver.

Method: The day reports of the official sport psychologist were analysed. Intervention issues were labelled using categories derived from previous research and divided into the following four intervention-issue dimensions: "general performance", "specific Olympic performance", "organisational" and "personal" issues. Data were analysed using descriptive statistics, chi square statistics and odds ratios.

Results: Across the Olympic Games, between $11 \%$ and $25 \%$ of the Swiss delegation used the sport psychology services. On average, the sport psychologist provided between 2.1 and 4.6 interventions per day. Around $50 \%$ of the interventions were informal interventions. Around $30 \%$ of the clients were coaches. The most commonly addressed issues were performance related. An association was observed between previous collaboration, intervention likelihood and intervention theme.

Conclusions: Sport psychologists working at the Olympic Games are fully engaged with daily interventions and should have developed ideally long-term relationships with clients to truly help athletes with general performance issues. Critical incidents, working with coaches, brief contact interventions and team conflicts are specific features of the onsite consultancy. Practitioners should be trained to deal with these sorts of challenges.

Keywords: Olympic Games, onsite interventions, brief contact intervention, crisis intervention, critical incident, psychology consultancy 


\section{Analysis of sport psychology consultancy at three Olympic Games: Facts and figures}

Competing at the Olympic Games is often considered the pinnacle of an athletic career

(McCann, 2008). Its 4-year cycle makes the Olympic Games an exceptional event for

athletes. Other factors contributing to its uniqueness are its multisport context and the

immense media interest surrounding it. During the Olympic Games, sports, which normally

do not arouse much public interest, are, for a short period, in the media's keen, but also

unforgiving, focus. Haberl and Peterson (2006) concluded that competing at the Olympics is

similar to being in a crucible that produces extraordinary pressures for all persons involved,

whether athlete, coach or other support staff. The Olympic experience can be the reward for a

long period of hard work, systematic preparation and suffering. If athletes succeed at the

Games, not only does their previous investment (financial and effort) pay off, but also they

might secure funding for the future (Haberl \& Peterson, 2006; Pensgaard, 2008).

In their quest for Olympic success, many nations have increased their scientific support.

Additionally, many sport associations and National Olympic Committees (NOCs) have integrated sport psychological services during the build-up to and at the Games itself (e.g.

Blumenstein \& Lidor, 2008; Samulski \& Lopes, 2008). Consequently, the demand for scientific knowledge regarding psychological factors influencing or associated with successful Olympic performance has risen. There is a substantial amount of literature on the Olympic experience of athletes and on practise reports of Olympic consultants (for a review, see Gould \& Maynard, 2009).

However, little research has been done on the most common psychological challenges and demands that sport psychologists face at the Olympic Games. For example, little is

61 known about the number and type of interventions a sport psychologist has to deal with, which type of client he or she will most likely work with and which additional factors will most likely influence associated collaborative efforts (e.g., previous collaborations between 
sport psychologist and athletes/coaches). Answers to these questions would be valuable not only for sport psychologists in order to prepare themselves for an Olympic mission but also for National Olympic bodies to plan the assignments of sport psychologists and develop the functional specifications for such specialists within the support staff.

Research related to the specific onsite challenges and demands faced by sport psychologists at the Games and which may provide some insights, include (a) research on stress and coping in sports, (b) evaluations of the Olympic experience of athletes and coaches and (c) best-practise reports on onsite psychology consultancy.

\section{Research on stress and coping of high-performance athletes}

One can view seeking the support of a sport psychologist as an attempt to cope with the demands of a specific situation, where athletes/coaches consider their coping resources or strategies to be inadequate to the situational requirements. Not surprisingly, sport psychologists have been interested in examining various sources of perceived stress in elite athletes. To explore organisational stress issues, researchers have predominantly used qualitative methods. Woodman and Hardy (2001) proposed a theoretical framework for organisational stress that was also used by Fletcher and colleagues (Fletcher \& Hanton, 2003; Hanton, Fletcher, \& Coughlan, 2005; Mellalieu, Neil, Hanton, \& Fletcher, 2009). They interviewed elite athletes with regard to potential sources of organisational stress while preparing for major international competitions (the Olympics and World Championships).

Within this framework, issues that are directly related to sport performance are deemed to be competitive stressors, whereas issues that are not directed to sport performance are regarded as organisational stressors. Frequency analysis revealed that participants mentioned competitive stressors less often than organisational ones. However, Mellalieu et al. (2009) saw a need to investigate stressors encountered by elite athletes directly within the competition environment and primarily related to competition. Using a similar methodology, 
they focused on both competitive and organisational stressors experienced by elite athletes in the hour before competition. Inconsistent with earlier research, their findings demonstrated a similar number of performance and organisational stressors directly before a competition.

Perhaps because of the temporal proximity to competition, more competitive stressors were present, as compared to earlier studies. Nevertheless, a significant number of organisational stressors were observed, demonstrating that these factors influence athletic performance 1 hour before the competition.

\section{However, while these researchers widened the focus concerning performance and} organisational demands involved in athletes' preparation and competition, they failed to consider that the personal environment (e.g., differences of opinion with a significant other) may also affect an athlete's performance. Thus, factors beyond the scope of organisational and competitive demand also need to be addressed to understand the overall stress elite athletes experience.

\section{Evaluations of the Olympic experience}

Gould and colleagues investigated factors influencing athletes' Olympic performance success (Gould, Greenleaf, Chung, \& Guinan, 2002; Gould, Guinan, Greenleaf, \& Chung, 2002). For this purpose, 296 Atlanta and 83 Nagano U.S. Olympians as well as 46 Atlanta and 19 Nagano U.S. coaches rated the frequency and perceived impact of different factors on performance. Following Gould and colleagues' rationale and on behalf of the Swiss Olympic Association, Schmid (2005a) conducted a similar study with 87 Swiss Athens Olympians. These Olympians indicated whether they faced any of 33 specific potential stressors and whether they were negatively or positively influenced in their Olympic performance by these potential stressors. A high percentage of athletes were challenged by "good results of opponents before the games" (91\%), "absolutely wanting to excel - high expectancies of self" (90\%), "high coach expectations" (74\%) and "lack of experience with Olympic 
114 specifics" (61\%). In contrast, relatively few athletes faced "safety worries" (5\%), "a lack of

115 information regarding their competitors" $(5 \%)$ or a "change of direct pre-event preparation"

$116(6 \%)$. More significant than the mere presence of such potential stressors, however, is their

117 ascribed positive or negative influence on Olympic performance. The following 12 stressors

118 had the strongest influence on the athletes' performance: “difficulties keeping cool in

119 challenging performance situations", "feeling of physical limpness", "difficulties in

120 recovering", "lack of confidence in the coach's abilities", "lack of financial support",

121 "disruption in the direct pre-event preparation through unforeseen distractions", "unfair

122 umpire decisions", "lack of experience with uniqueness of Olympic competition", "bad

123 timing of competitions before the Olympics", "head coach's incompetence", "change in the

124 direct pre-event preparation" and "self-allegations during the Olympic competition".

125 To narrow down the factors for a possible intervention, Schmid (2005b) explored which

126 factors had both a considerable negative impact and with which a significant number of

127 athletes were challenged. This increased the list by eight factors: "lack of preparation for

128 unexpected events and unforeseen distractions at the Olympics", "lack of familiarity with

129 competition venue", "absolutely wanting to excel", "pressure due to great expectations",

130 “challenging media demands", "sleep-onset and sleep-maintenance difficulties" and

131 "unfamiliar weather/climatic conditions". All in all, 20 factors were identified as being

132 relevant to Olympic performance success. These findings not only underline U.S. Olympic

133 committee sport psychologist Sean McCann's idea (2008) that "at the Olympics, everything

134 is a performance issue" (p. 267) but also serve as a cornerstone on which the Swiss Olympic

135 Association built their preparation for the Olympic Games of 2006, 2008 and 2010.

Best-practise reports on onsite psychology consultancy

Another valuable source for preparing psychologists for onsite services are best-practise reports on effective Olympic psychological consultations. McCann (2008) reported on the 
139 wide scope of issues U.S. sport psychologists faced at the Games. He mentioned (a) clinical

140 issues, such as suicidal ideation, depression, mania, compulsion, eating disorders; (b)

141 problems with the adjustment to external factors (e.g., death of a family member, homicide

142 by a friend, legal charges and marriage crisis); (c) financial crisis or drug-testing uncertainty;

143 (d) interpersonal conflicts (e.g., conflict with agent, coach or teammate); (e) distractions at

144 the Games, like issues with sexuality, the media and sponsors and (f) performance pressures

145 due to coaches, the media, parents, significant others, agents and internal standards. This list

146 shows that sport psychologists, as well as athletes and coaches, should prepare themselves for

147 a wide variety of issues.

148 The literature concerning Olympic mental skills training programmes (e.g., Blumenstein

149 \& Lidor, 2008) focuses on psychological skills training prior to the Games. But as

150 highlighted above, athletes might want to address a wide range of additional challenges and

151 issues with a sport psychologist during the Olympics. This appraisal is supported by Hodge's

152 (2010) review of the literature. He pointed out several mental issues as being relevant and

153 common to the Olympic environment. Particularly, he identified stress management and

154 coping with stressors, such as transport, security and organisational hassles, living in the

155 village and dealing with the disappointment of a poor performance as the most commonplace

156 challenges faced by Olympians. Additionally, Olympic athletes need to fine-tune their pre-

157 event mental preparation to meet the special demands of the Games environment. Other

158 psychological consequences emerge from interpersonal conflicts between athletes, sometimes

159 with coaches or team managers, as well as from injury, fear of injury, re-injury or illness.

160 Another phenomenon described by Hodge (2010) is the so-called second week blues. He

161 observed that the smooth athletic and psychological functioning of many members of the

162 Olympic team is affected by irritability or homesickness after the first week of living in the

163 Olympic environment. Further, friends and family members of competing athletes attend the 
164 Games to support their athletes. However, this is most often new for the athlete and might be an extra distraction and additional source of stress.

166 Onsite sport psychology consultancy at the Olympic Games differs in not only the issues

167 raised by clients but also in the consultation setting itself. While most of the interventions in

168 the preparation phase are typically scheduled and planned, many at the Olympics are informal

169 in nature and not planned. Initial contacts where athletes or coaches approach the

170 psychologist in a casual, unforced situation help build social bridges and may well emerge as

171 small interventions. They are often as effective as scheduled sessions and frequently lead to a

172 traditional, more structured one-on-one consultation (Vernacchia \& Henschen, 2008).

173 Given the unique schedule and pace of the Games, these field interventions are critical

174 elements for success. Despite the informal character of many of these interventions, they

175 should follow a certain protocol or employ a certain structure. Giges and Petitpas (2000) refer

176 to such intervention strategies as "brief contact interventions", i.e. a single, unplanned

177 professional interaction of short duration (15-20 minutes) taking place between client and

178 practitioner "where clients are able to gain new perspectives on their present situations" (p.

179 177). The intervention normally employed in these informal situations is focused on

180 performance enhancement. Other important psychological issues, even though they are

181 visible, remain intentionally unexplored. According to Giges and Petitpas (2000), such

182 interventions should be solution-focused, action-oriented, goal-oriented to a single

183 manageable problem at any moment and supportive and convey a sense of control. However,

184 to the best of our knowledge, data are not available on the frequency of this type of

185 intervention or on the clients (e.g., athletes, coaches, team managers and medical staff) who

186 call for such onsite sport psychology support. 
psychological services it provided to its delegation members and therefore integrated a sport psychologist into its team. The reason for this expansion was that during the 2000, 2002 and 2004 Olympics critical incidents happened that seriously jeopardised the functioning of at least a subsystem of the Olympic delegation. Thus, since the 2006 Olympic Games in Turin, a sport psychologist has been a fully integrated and accredited staff member of the Swiss Olympic team in order to be prepared for such emergencies. The sport psychologist received AO accreditation as part of the team's medical personnel with full access to the Olympic village and competition sites. The sport psychologist was accommodated in the Olympic village. If more than one Olympic village existed, however, he was assigned to a temporary accommodation in the village where his service was required.

As a member of the medical team, he needed to report directly to the chief medical officer and the "chef de mission" of the Swiss Olympic team. The position, function and role of the sport psychologist evolved in the three Olympic Games covered. Because of his appreciated work, he was selected as a member of the executive board of the Swiss Olympic delegation in 2010. In order to get acquainted with the athletes and coaches, the sport psychologist participated in the Swiss Olympic pre-events, that is, two days of meetings for athletes, coaches and delegates of the sports federations. They are held in the eighth or ninth month before the Olympics with the goal to prepare the participants for the upcoming Olympic season and sensitise them for the unique challenges of the Olympic Games. The 2006 Olympic Games, however, were an exception, because the decision to integrate a sport psychologist in the Swiss team was made after the Olympic pre-event. As a consequence, the sport psychologist joined the chief medical officer and visited prior to the Games all sporting teams in training camps or competitions. In 2008 and 2010, the sport psychologist held preparatory workshops (e.g., how to react in crisis situations) for the medical staff, the delegation leaders of the different sporting federations and the executive board. The main 
214 task was to educate the participants on how to react in crisis situations.

215 To select the official sport psychologist, the Swiss Olympic Association identified several

216 criteria. The sport psychologist in question should have several years of experience in applied

217 work with coaches and athletes. He should have a good reputation with athletes, coaches and

218 the Swiss Olympic officials as well as an education in or practical knowledge of crisis

219 interventions. Finally, the sport psychologist in question should be a team player and should

220 be able to work closely with the chief medical officer and the Swiss Olympic "chef de

221 mission".

222 Taking into account the lack of data on onsite sport psychology consultations at Olympic

223 Games, the aim of this paper is to address the onsite work of the aforementioned official sport

224 psychology consultant for the Swiss Olympic team. The findings are based on the hands-on

225 experience gained during onsite counselling at one Summer (Beijing, 2008) and two Winter

226 Games (Turin, 2006; Vancouver, 2010). In particular, this paper will firstly, quantify the

227 intervention frequency, the types of interventions, the types of clients and their issues.

228 Secondly, it aims to explore how previous collaboration between the sport psychologist on

229 the one hand and athletes or coaches on the other affects the demand for onsite sport

230 psychology consultancy at the Olympic Games.

\section{Methods}

\section{Personal characteristics of the sport psychologist}

The official sport psychologist was 37 years old and had 8 years' experience working with athletes and coaches when he was appointed in 2005. He had master degrees in physical education and educational psychology. He was further trained as a sport psychologist and participated in the Post Graduate Sport Psychology Curriculum (Wylleman, Harwood, Elbe,

237 Reints, \& de Caluwé, 2009). Finally, his professional education was complemented by

238 extensive training in crisis intervention (Certificate of Advanced Studies in Crisis 
239 Intervention). The sport psychologist has a background as a high performance athlete in

240 military pentathlon: He was a long-time member of the Swiss national team and competed at

241 the highest international level (World and European Championships).

\section{Data}

243 The sport psychologist kept a diary, in which he recorded his daily meetings,

244 interventions and personal experiences. If conditions did not allow him to take notes

245 immediately, he took notes later in the day. At a later stage, the sport psychologist recorded

246 all intervention data (interventions lasting for more than 15 minutes) to an Excel file to be

247 able to report his work to the NOC. These day reports have been systematically analysed for

248 this paper. All planned and scheduled interventions were labelled as formal interventions. All

249 unplanned and non-scheduled contacts lasting more than 15 minutes concerning a

250 psychological issue were labelled as informal interventions (brief contact interventions).

251 Generally, the athletes and coaches sought contact with the sport psychologist on their own.

252 When the physician advised the athlete in a medical consultation to seek psychological

253 counselling, contact was made by the medical doctor. The decision to log a contact as an

254 intervention was sometimes ambiguous. Small talk was differentiated from an intervention

255 based on the subjective judgement of the sport psychologist as to whether he was approached

256 in his role as sport psychologist. Thus, when he felt that a contact was made out of personal

257 interest, he did not log it as an intervention. Daily meetings of the medical team and of the

258 executive board (Vancouver) were not counted as interventions. From the 2006 Olympic

259 Winter Games in Turin onwards, the sport of the clients was recorded. For the 2008 Olympic

260 Summer Games in Beijing and the 2010 Olympic Winter Games in Vancouver the name, sex

261 and intervention issues were recorded as well. The logging of the onsite work started with the

262 departure from Switzerland to the Olympic venues and ended with the arrival in Switzerland

263 after the end of the Games. 
Procedure

The day reports were analysed by the first author of this paper. All single interventions were treated as individual cases. In all cases, the sport, the intervention form

267 (formal/scheduled and planned vs. informal/brief contact intervention), the client group 268 (individual athlete, team, coach/head coach, member of medical team, executive board member or others), the intervention issues (maximum of four issues per intervention) and the

270 client's name and sex were included. To establish meaningful intervention categories, the 271 intervention issues were labelled using the success and failure factors identified in previous studies by Schmid (2005a, 2005b). Factors that were not relevant during the Games, for example, "alterations in the familiar training concepts in the season leading up to the Olympic Games", and factors that did not emerge as relevant for Swiss athletes in previous studies (Schmid, 2005a), for example, "spectators/crowd behaviour at the Olympics", were not included in the raw categories. Twenty-five out of the original 33 relevant success and failure factors were used for possible categorisation. This list was completed with six additional themes emerging from previous reports from sport psychology practitioners about their experiences and issues raised at the Games (Hodge, 2010; McCann, 2008; Mellalieu et al., 2009). These were "competition debriefing", "critical incidents" (any event that causes an unusually strong emotional reaction that has the possibility of interfering with the ability to function normally), "social/personal issues" (issues that arise directly from the athlete's personal life), "nutritional issues" (psychological distress stemming from dieting or nutritional demands), "injury/illness" (distress that arises from fear of injury/illness, injury/illness itself or psychological dysfunctions, such as depression) and "non-specific performance issues" (stressors that arise directly from the competition, but are very broad and could not be summarised under the other raw categories). For the purpose of verification and trustworthiness, labelling consensus between the first and second author (the official sport 
psychologist of the Swiss Olympic team) of the present paper was sought. Using the aforementioned framework for organisational stress (Fletcher \& Hanton, 2003; Hanton et al., 2005; Mellalieu et al., 2009), these raw themes were clustered into higher-order themes. In turn, the higher-order themes were categorised under four dimensions or first-order

293 dimensions of greatest generality. This selection was based on the literature (Fletcher \&

294 Hanton, 2003; Hanton et al., 2005; Mellalieu et al., 2009): (1) "general performance issues"

295 (competitive stressors pertaining directly to competitive performance), (2) "specific Olympic

296 performance issues" (competitive stressors pertaining primarily to the uniqueness of the

297 Olympic competition), (3) "organisational issues" (organisational stressors pertaining to the

298 sport environment in which the performer is primarily operating) and (4) "personal issues"

299 (stressors pertaining directly to the individual, his or her personal history and the personal or 300 private environment to which the athlete primarily relates).

\section{$301 \quad$ Data analysis}

302 To explore the frequency of interventions, types of interventions and client groups, 303 descriptive statistics were used. Due to the categorical character of most of the variables, a 304 series of chi square analyses were performed to examine the associations between variables.

305 Where appropriate, odds ratios $(O R)$ were calculated to present easily interpretable measures 306 of effect size. To decide whether there are differences between the results for the provision of 307 onsite sport psychology services at the three respective Olympics, odds ratios were used.

\section{Results and discussion}

309 Number of interventions, type of services and client groups

310 The number of interventions for all three Olympic Games is presented in Table 1. Not

311 included in these statistics are the daily meetings the official sport psychologist had to attend:

312 the meetings of the medical team from 6:00 to 6:30 am (Turin, Beijing and Vancouver) and

313 the meetings of the executive board in Vancouver (6:30 to 7:00 am). The number of 
314 interventions increased from 40 interventions at the Olympic Games in Turin to 102 in

315 Beijing and 70 in Vancouver. This corresponds with an average of 2.1 interventions per day

316 in Turin, 4.6 interventions in Beijing and 4.0 interventions in Vancouver. The number of

317 daily interventions ranged between 0 and 9 for the three Olympics. In Beijing 2008, owing to

318 contact with infected athletes, the sport psychologist was quarantined for 2 days, so he could

319 perform no interventions or only minor ones using Skype and a phone. In Beijing, 22 athletes,

32016 coaches and 3 medical personnel sought sport psychology support, in contrast with the 20

321 athletes, 10 coaches and 2 members of the medical staff in Vancouver. As the number of

322 accredited athletes, coaches and medical staff differs from Games to Games, the pertinent

323 numbers are also presented in Table 1.

324 We interpret the increase in the number of daily interventions as an indicator of the

325 enhanced acceptance and the quality of onsite psychological services. This interpretation is

326 supported by formal evaluations of the Games in Turin (Schmid, 2006) and Beijing (Swiss

327 Olympic Association, 2008). Although the number of daily interventions at the Olympics in

328 Beijing and Vancouver are comparable, the ratio of athletes, coaches and medical staff who

329 used sport psychology services were not. This is probably due to the traditionally larger

330 Swiss delegation at the Winter Games and the sport psychologist's shorter presence at the

331 Winter Games. Another reason might be that with two Olympic villages (Vancouver and

332 Whistler), the sport psychologist was much less visible or approachable for a substantial

333 number of athletes and coaches. However, at 25\% (Beijing) and 11\% (Vancouver), a

334 significant proportion of the delegation members consulted the sport psychologist, which

335 underlines the importance of sport psychology services. The number of interventions per

336 individual (athletes, coaches or members of the medical staff) averaged three sessions for

337 both Beijing and Vancouver. Number of contacts ranged between 1 and 15 occasions,

338 demonstrating that some athletes had a very intense professional relationship with the service 
339 provider. The number of daily interventions, which ranged between 0 (due to medical

340 quarantine) and 9 per day, also indicates that onsite work cannot be scheduled in as in other

341 settings.

342 The ratio between formal, scheduled and planned interventions on the one hand and

343 informal, unplanned brief contact interventions on the other hand ranged between $60 \%: 40 \%$

344 (Turin), 48\%:52\% (Beijing) and 56\%:44\% (Vancouver). This shows that brief contact

345 interventions have been a cornerstone in the delivery of sport psychology services for the

346 Swiss Olympic team. The findings highlight the importance this counselling method has in

347 the context of the Olympic Games and underlines that sport psychologists working at the

348 Games should learn to perfect "the ski-lift consult, the bus-ride consult, the 10-minute

349 breakfast table teambuilding session, and the confidential session in public places such as

350 hotel lobbies, parking lots, and trainers' tables" (McCann, 2000, p. 211). Contrary to the

351 concept of brief counselling interventions proposed by Giges and Petitpas (2002), our

352 analyses revealed that multiple, rather than single, issues were discussed in a single

353 intervention session. This might be due to the significance and urgency the client and sport

354 psychologist ascribed to the issues in the hour before competition. Therefore, they tried to

355 tackle all issues raised.

356 The official sport psychologist for the Swiss Olympic team provided individual sessions

357 for athletes, coaches and members of the medical staff, group sessions for athletes and

358 coaches and competition observations, including feedback to athletes and coaches. For the

3592008 and 2010 Olympics, Table 2 shows a breakdown of the frequency of each type of

360 services subdivided into the aforementioned client groups. Individual sessions with athletes

361 were the most frequent form of intervention in Beijing (40\%) and in Vancouver (41\%).

362 Individual sessions with coaches or head coaches were the second most frequent intervention

363 (Beijing: 38\% and Vancouver: 27\%) followed by group sessions (Beijing: 13\% and 
364 Vancouver: 19\%). A small proportion of interventions were also held with other persons,

365 such as athletes' family members. These findings support Hodge's (2010) notion that coaches

366 constitute a substantial proportion of clients. However, athletes are still the largest client

367 group. The considerable number of group sessions highlights that sport psychologists

368 working at the Games need to have group managing and group counselling skills. Another

369 form of service was competition observations (around 6\%), emphasising the need for

370 behavioural observation skills as well. Consequently, applied practitioners working at the

371 Olympics may need to broaden their competencies to work with coaches and to undertake

372 behavioural observations in the competition setting.

\section{Intervention issues}

$374 \quad$ Figure 1 depicts all intervention issues raised in the provided onsite sport psychology services during the Games in Beijing and Vancouver. A total of 170 issues were raised in 102 interventions in Beijing, and 159 themes were discussed in the 70 interventions in Vancouver. The analysis of these issues supports the findings of previous studies that the perceived stressors at the Olympics are complex or, at least, multiple. In the Olympic context, where coming fourth is often regarded as a failure, "general performance issues" are the ones most frequently addressed by athletes and coaches at the first-dimension level. In Beijing, approximately $75 \%$ of the intervention issues related to this category; in Vancouver, however, this percentage was around 50\%. Self-regulation, direct pre-event mental preparation and expectations/goal issues are the most common themes within this category.

384 Athletes and coaches seem to be caught up in the pressure and high expectations - issues that

385 may best be addressed by identifying specific process goals separately from the overwhelming outcome goals at the Games. In contrast, self issues (self-allegation and selfefficacy) and recovery issues were seldom addressed. 
before their potentially career culminating competition? In Beijing, $6 \%$ of the interventions were regarded as "personal issues" and in Vancouver 26\%. This difference is because of the higher percentage of "critical incidents" (13\%) and social issues $(10 \%)$ such as the death of a close person arising at the Games in Vancouver. The rate for "organisational issues" was comparable in Beijing (16\%) and Vancouver (18\%). Within this category, "conflicts or frictions within the team" were addressed at just under $10 \%$, and "lack of confidence in the coach's ability" or "head coach's incompetence" were relatively frequent (7\% and 4\%, respectively) in being identified as issues. In terms of the higher-order themes and the raworder themes, "specific Olympic performance issues" were seldom discussed ( $2 \%$ for Beijing and $6 \%$ for Vancouver). Within the "general performance issues" dimension, "pre-event mental preparation", "expectations" and "self-regulation" were raised relatively often.

Regarding the ratio between competitive and organisational stressors apparent in elite athletes, the analysis reinforces Mellalieu et al.'s (2009) findings that in the hour before competition the perception of organisational stressors is reduced and the perception of competitive stressors enhanced. It is likely that because of the temporal proximity to their competition athletes seem to try to focus their attention predominantly on their performance delivery. In this study, less than $20 \%$ of interventions were due to organisational stressors. However, one can assume that if perceived organisational stressors are impacting an athlete's performance, he or she will seek counselling. Conflicts within the team and lack of confidence in the (head) coach's abilities were identified as the most common organisational stressors. The relationship between any athlete and his or her coach and team functioning seem to be critical factors for athletes to be able to believe in their ability to fulfil their own potential. Therefore, these issues need to be immediately tackled to smooth the road to success.

Some of the abovementioned results deserve further examination. For example, in light of 
414 Schmid's (2005a) findings, it is perhaps surprising that specific Olympic performance issues

415 (as well as recovery issues) have been seldom addressed in sport psychology consultations.

416 This absence of discussion might be because these issues have already been explored in

417 manuals, brochures and pamphlets for athletes and coaches provided by the Swiss Olympic

418 Association for all three Olympics in question (e.g., Birrer, 2009; Birrer \& Wetzel, 2009). In

419 a formal evaluation, athletes stated that the information provided was relevant and

420 informative (Schmid, 2006).

421 The fact that coaches constitute an important client group raises the question of whether

422 coaches and athletes share the same consulting issues. The data suggest that there is no

423 difference between coaches and athletes with regard to frequency of consulting except for

424 Beijing, where coaches were nearly two times more likely to raise organisational issues than

425 athletes $(O R=1.88)$ and for Vancouver, where coaches were more than three times more

426 likely than athletes to discuss an organisational issue $(O R=3.65)$. Given the specific

427 demands of these two client groups, the issue difference makes sense. For coaches, the

428 challenge is to organise everything around their athletes to enable them to compete at their

429 highest possible level, whereas for athletes the challenge is mainly on the competition side.

430 Effects of previous collaborations

431 Do previous collaborations between a sport psychologist and a client influence the

432 probability to seek onsite support at the Olympic Games? In fact, a significant association

433 between earlier collaboration with the sport psychologist and whether clients would seek his

434 service (again) was found with $\chi^{2}(1, N=163)=54.65, p<.001$ in Beijing 2008 and $\chi^{2}(1, N=$

$435258)=66.15, p<.001$ in Vancouver. This effect is quite large, as the Phi values show

436 (Beijing: $\Phi=.58$; Vancouver: $\Phi=.51$ ). Based on the odds ratios, athletes or coaches who

437 worked before the Olympics with the sport psychologist were 52 (Beijing) and 12

438 (Vancouver) times more likely to approach him for consultancy. Previous contact with the 
sport psychologist was also associated with the issues raised in the interventions. Chi square statistics show a significant association between earlier collaboration and the first-order

441 dimensions in our study for Beijing $\left(\chi^{2}(3, N=172)=13.51, p<.01\right)$ and for $\operatorname{Vancouver}\left(\chi^{2}(3\right.$, $N=159)=31.84, p<.001)$. For Vancouver, no significant association was found between previous contact and "specific Olympic performance issues" $\left(\chi^{2}(1, N=159)=0.10, p=.75\right)$ and previous contact and "organisational issues" $\left(\chi^{2}(3, N=159)=0.20, p=.66\right)$. However, for Vancouver, previous contact seemed to have a significant association with "personal issues" raised as an intervention theme by athletes $\left(\chi^{2}(3, N=159)=28.11, p<.001\right)$ and "general performance issues" $\left(\chi^{2}(1, N=159)=18.74, p<.001\right)$ as an intervention theme: In the case of a "personal issue" (e.g., a critical incident), athletes or coaches who did not work with the sport psychologist before the 2010 Olympics were seven times more likely to approach him than athletes or coaches without previous collaboration with him. The opposite seems to be true for "general performance issues": athletes or coaches who worked with the sport psychologist before the Vancouver Games were 4.5 times more likely to approach him because of a "general performance issue". However, the chi square analyses for Beijing showed no association between previous collaboration on the one hand and "general performance issues" $\left(\chi^{2}(1, N=172)=0.50, p=.48\right)$ and "organisational issues" $\left(\chi^{2}(1, N=\right.$ $172)=1.37, p=.24$ ) on the other. On the contrary, there seems to be an association between previous collaboration and "specific Olympic performance issues" as well as personal issues raised in the intervention (such as the death of someone close). Still chi square assumptions were not met because several expected frequencies were below five. Therefore, those results 460 are not detailed here. Finally, previous contact with the sport psychologist had no influence 461 on whether the interventions were planned (Beijing: $\chi^{2}(1, N=102)=1.78, p=.18, \Phi=-.13$; Vancouver: $\left.\chi^{2}(1, N=70)=.43, p<.52, \Phi=-.08\right)$. 
psychologists' working with the athletes before the Olympics so that they can help a considerable number of athletes to successfully cope with competitive stressors faced at the

Games. The findings are not consistent though. They suggest that previous collaboration might be an influencing factor for clients to approach the sport psychologist. Yet previous collaboration is not a requirement, especially if the support-seeking person's reason is a critical incident or another personal issue with significant consequences, as our analysis of the Vancouver data indicate.

\section{General discussion}

This study extends recent practise reports investigating the consultancy work of sport psychologists involved in helping athletes and coaches cope with the Olympic experience (e.g. Hodge, 2010) and achieve their best possible performance at the Games. In particular, the fact that this study investigated the sport psychology services provided at three different Olympics allowed for the exploration of intervention differences and possible influencing factors. As other scientists have suggested (Mellalieu et al., 2009), this study distinguishes four types of challenges athletes and coaches face in light of a major sport event. The findings support Mellalieu et al.'s (2009) assertion that personal and organisational issues may indeed become a performance issue in the competition arena. Thus, as "general performance issues", "specific Olympic performance issues", "organisational issues" and "personal issues" were all relevant counselling topics in the investigated Olympic missions, sport psychologists working at the Olympic Games have to be prepared to help their clientele to cope with all abovementioned challenges.

One reason the executive board of the Swiss Olympic Association decided to integrate a sport psychologist into the onsite support staff was to have a specialist present to handle critical incidents. However, neither at the Olympics in Turin nor at the Olympics in Beijing did a major critical incident (e.g. life threatening injury within the team) take place. This 
might be due to a preventative effect of the work of the sport psychologist with a part of the clientele prior to the Games and at the Games itself. This interpretation is supported by the

491 fact that in Vancouver athletes who worked previously with the sport psychologist were less

492 likely to approach him with a personal issue. Additionally, in Beijing, only in $6 \%$ of the

493 interventions was a personal issue the main cause. However, in Vancouver, the fatal accident

494 of a Georgian luge Olympian, eye-witnessed by Swiss athletes and a coach, made a crisis intervention essential. Following this casualty, several Swiss bob sleighs overturned in practise runs, and one athlete was severely injured and fortunate to escape permanent disability. These events also led to $4 \%$ of the themes in Vancouver concerning health issues, as some athletes doubted the security of the bob run. Such situations are ethically challenging

499 for the sport psychologist, who has to take responsibility for how much he can push an athlete to overcome pain and fear. The handling of a crisis can generally not be put off until later, and the sport psychologist needs to deal with the immediate problem and prevent potential future ramifications (McCann, 2008). Consequently, resources are tied up, and the sport psychologist may not be available for athletes with performance issues. This is reflected in the decrease in interventions at the Vancouver Olympics, with performance issues being under $50 \%$. This must be considered in the provision of an effective onsite psychological service, and back-up plans need to be prepared in advance.

While critical incidents are stressful for the sport psychologist, too, other factors make the onsite work even more stressful, for example, the limited time frame that the Olympic setting offers for interventions, the transport, security and organisational difficulties at the Games

510 (Hodge, 2010) or the many interventions per day. All in all, a 14-hour working day is more 511 the rule than the exception for a sport psychologist at the Olympics. Additionally, Olympic

512 Games usually take longer than World Championships. Considering the time for acclimatisation, an Olympic mission may therefore take 20 days or longer. This can also be 
an additional source of strain for a sport psychologist. In sum, Olympic Games are an unrivalled challenge for not only athletes and coaches but also sport psychologists. The expectations are for all, the sport psychologist included, extremely high. All participants take

517 the Games and the Olympic competition extremely seriously. Above all, the sport

518 psychologist often fulfils multiple functions. For example, he is not responsible for one single

519 team but for several. Moreover, one moment his services might be requested at a flower ceremony for an athlete with whom he is working, and the next moment he has to conduct a crisis intervention with athletes/coaches from another sport. All things considered, the factors that make the Olympic Games exceptional for athletes and coaches apply for the sport psychologist, too. argue that onsite consultancy cannot be successful unless the sport psychologist and his or her clients have worked together prior to the Games. And since in a medium-sized Olympic team,

527 a large number of sport psychologists might be involved in the preparation of athletes, many sport psychologists should be integrated into the onsite support team - an idea that is unfeasible given the restricted number of accreditations allotted to an official delegation. While this reasoning has some appeal, this study demonstrates that a previous collaboration is not a prerequisite for successful onsite support, especially if the intervention request is a "personal" or "organisational issue". Furthermore, psychologists are trained to build up a professional relationship by creating a safe, confidential atmosphere and mutual trust.

Another argument often raised is that there should be no need for onsite sport psychological support because if so, the athlete or coach would not have been well prepared prior to the Games. Beyond doubt, preparing for the Olympic challenge is a long-term

537 process. But again, critical incidents, personal crises or even performance slumps due to 538 perceived pressure can always occur and become performance factors. In these cases, the 
onsite sport psychology service could support long-time psychological preparation. An anecdotal example to support this statement is the story of the male curling team from the 2010 Olympics. After a series of bad games with a huge performance slump, the team recovered after several interventions and finally won the Olympic bronze medal.

543 These thoughts lead to reflections on best practise models for onsite sport psychology

544 service delivery. Since crisis situations, which require some sort of onsite specialist

545 intervention, will almost inevitably occur, integrating a well-trained sport psychologist in the

546 NOC delegation is prudent. The sport psychologist's duty could include providing support to

547 the executive board, being available for crisis situations and helping athletes and coaches

548 with performance issues. As not all athletes and coaches can profit from such a service

549 because of the sport psychologist's limited time resources, a NOC might consider integrating

550 additional sport psychologists who were already working in the support team of selected

551 federations in the years leading up to the Games. This might be a particularly good solution

552 for federations which have private external accommodations to reduce the travelling from the

553 Olympic village to their competition and training venues. For this purpose, the sport

554 psychologist must have full access to the Olympic village(s) and competition sites. This

555 might be guaranteed with day accreditations. The assignments for these sport psychologists

556 are limited to the time the competition lasts for the relevant sport. This solution allows more

557 athletes and coaches to profit from sport psychology services. Additionally, doing so might

558 guarantee that in the case of crisis intervention the "back-up" psychologist can work with

559 their federations on performance issues.

In this paper, we explored the onsite sport psychology service of an official sport

562 psychologist responsible for the service provision of a small country's Olympic delegation.

563 One of the most important conclusions from this analysis is that the sport psychologist is 
564 fully involved with daily interventions (not counting staff meetings) and ideally but not necessarily should have had a long-term relationship with the clients in order to have an impact on general performance issues, particularly in the case of a team. Therefore, the assigned practitioner has to be able to work under pressure. However, athletes and coaches will address personal or organisational issues, whether they have worked with the sport

569 psychologist before the Games or not. Critical incidents of any kind require substantial resources from the sport psychologist. This, in turn, limits the resources available for the onsite support of other athletes and coaches and will severely handicap a sport psychologist's chances of creating a performance impact, which usually is the main reason for a NOC to include a sport psychologist in the onsite support team. Furthermore, the logistical prerequisites of the Olympic Games will constrain the impact of the sport psychology services, for example, when there are different Olympic villages and the consultant is working without the accreditation to allow for access to the clients. NOCs are well advised to consider these facts when specifying sport psychologists' functions and planning their assignments. The Swiss Olympic Association, for example, might increase their sport psychology support staff for the 2012 Olympics with a sport psychologist mainly responsible for the executive board and critical incidents, and consultants, previously working with the respective sports, mainly present for performance issues. This will also be advantageous in terms of having colleagues around for peer consultation or "back-up", e.g. in case of illness. of sport psychologists (see also Wylleman et al., 2009) who are to work for a delegation at the Games. It is likely that the sole use of psychological skills training will prove rather

586 ineffective in tackling many of the issues with which participants are confronted. Applied

587 practitioners working at the Olympics need to broaden their competencies to do justice to their clients and the issues they could potentially face. Thirty per cent of the clients might be 
coaches, $50 \%$ of the interventions might be brief counselling interventions and a considerable share of the issues might be related to conflicts or frictions within the team. Additionally,

591 critical incidents will likely occur, and the sport psychologist should be capable of handling

592 them. All this has to be integrated in the training for sport psychologists delivering services at

593 the Games. The continued professional development initiative 'Psychological Excellence for

594 Elite Performance' (PE4EP) developed by the European Sport Psychology Federation

595 (FEPSAC) on the topic of conflict and crisis management in elite and Olympic sport

596 (FEPSAC, 2012) as well as the Forum of Applied Sport psychologists in Topsport (FAST)

597 (Wylleman et al., 2009) anticipated this need in applied sport psychologists.

598 Although this paper provided some insights into the onsite work of a sport psychologist

599 acting at the Olympics, it can only serve as a starting point for future debate and research.

600 Further research is needed to evaluate the onsite work of a consultant and the relative impact

601 of the different forms of interventions, for example, whether a consultant in brief counselling

602 interventions should concentrate on the solution of just one issue raised or how well a single

603 sport psychologist can cope with the amount and duration of onsite work at Olympic Games. 
Birrer, D. (2009). Befindlichkeit: erkennen und beeinflussen der eigenen Stimmung [Quality of experience: Perceiving and influencing one's mood]. In Swiss Olympic Association (Ed.), Basics for success. Ratgeber zur optimalen Vorbereitung auf die Olympischen Spiele 2010 (pp. 67-73). Berne: Swiss Olympic Association.

Birrer, D., \& Wetzel, J. (2009). Mentale Vorbereitung auf einen Grosswettkampf [Mental preparation for a big event]. In Swiss Olympic Association. (Ed.), Basics for success. Ratgeber zur optimalen Vorbereitung auf die Olympischen Spiele 2010 (pp. 85-96). Berne: Swiss Olympic Association.

Blumenstein, B., \& Lidor, R. (2008). Psychological preparation in the Olympic village: A four-phase approach. International Journal of Sport \& Exercise Psychology, 6, 287-300. doi:10.1080/1612197X.2008.9671873

FEPSAC. (2012). Psychological Excellence for Elite Performance (PE4EP). Retrieved January 20, 2012, from http://www.fepsac.com/pe4ep/.

619 Fletcher, D. D., \& Hanton, S. S. (2003). Sources of organizational stress in elite sports performers. Sport Psychologist, 17, 175-195.

Giges, B. B., \& Petitpas, A. A. (2000). Brief contact interventions in sport psychology. Sport Psychologist, 14, 176-187.

Gould, D. D., Guinan, D. D., Greenleaf, C. C., \& Chung, Y. Y. (2002). A survey of U.S. Olympic coaches: Variables perceived to have influenced athlete performances and coach effectiveness. Sport Psychologist, 16, 229-250.

626 Gould, D. D., Greenleaf, C. C., Chung, Y. Y., \& Guinan, D. D. (2002). A survey of U.S. Atlanta and Nagano Olympians: Variables perceived to influence performance. Research Quarterly for Exercise \& Sport, 73, 175-186. 
629 Gould, D., \& Maynard, I. (2009). Psychological preparation for the Olympic Games. Journal of Sports Sciences, 27, 1393-1408. doi:10.1080/02640410903081845

631

632

633

634

635

636

637

638

639

640

641

642

643

644

645

646

647

648

649

650

651

652

Haberl, P., \& Peterson, K. (2006). Olympic-size ethical dilemmas: Issues and challenges for sport psychology consultants on the road and at the Olympic Games. Ethics \& Behavior, 16, 25-40. doi: 10.1207/s15327019eb1601_4

Hanton, S., Fletcher, D., \& Coughlan, G. (2005). Stress in elite sport performers: A comparative study of competitive and organizational stressors. Journal of Sports Sciences, 23, 1129-1141. doi:10.1080/02640410500131480

Hodge, K. (2010). Working at the Olympics. In S. J. Hanrahan \& M. B. Andersen (Eds.), Routledge handbook of applied sport psychology (pp. 405-413). London: Routledge.

McCann, S. C. (2000). Doing sport psychology at the really big show. In M. B. Andersen (Ed.), Doing sport psychology (pp. 209-222). Champaign, IL: Human Kinetics.

McCann, S. C. (2008). At the Olympics, everything is a performance issue. International Journal of Sport \& Exercise Psychology, 6, 267-276. doi:10.1080/1612197X.2008.9671871

Mellalieu, S. D., Neil, R., Hanton, S., \& Fletcher, D. (2009). Competition stress in sport performers: Stressors experienced in the competition environment. Journal of Sports Sciences, 27, 729-744. doi:10.1080/02640410902889834

Pensgaard, A. (2008). Consulting under pressure: How to help an athlete deal with unexpected distracters [sic]during Olympic Games 2006. International Journal of Sport \& Exercise Psychology, 6, 301-307. doi:10.1080/1612197X.2008.9671874

Samulski, D., \& Lopes, M. (2008). Counseling Brazilian athletes during the Olympic Games in Athens 2004: Important issues and intervention techniques. International Journal of Sport \& Exercise Psychology, 6, 277-286. doi:10.1080/1612197X.2008.9671872 
653 Schmid, J. (2005a). Was die Leistung im Olympiawettkampf beeinflusst: eine Befragung der 654 Schweizer Teilnehmer/innen an den Olympischen Spielen 2004 in Athen [Influences on the performance at the Olympic competition: A survey of the Swiss participants of the 2004 Olympic Games in Athens]. Unpublished manuscript, Department of Psychology,

Schmid, J. (2005b). Wie die Athletinnen und Athleten die Arbeit von Swiss Olympic im Kontext von Athen 2004 beurteilen: Eine empirische Untersuchung über die Möglichkeiten, die Leistungsvoraussetzungen an Olympischen Spielen zu optimieren [Services provided to the athletes by the Swiss Olympic Association: An evaluation from the perspective of the athletes participating in Athens 2004]. In Swiss Olympic Association (Ed.), Swiss Olympic Report 2004: Das Unternehmen Athen auf dem Prüfstand [Swiss Olympic Report 2004: Evaluation of the mission to the Olympic Games 2004 in Athens] (pp. 85-112). Berne: Swiss Olympic Association.

Swiss Olympic Association. (2008) Swiss Olympic team Beijing 2008. Swiss Paralympic team Beijing 2008. Final Report. Berne: Swiss Olympic Association.

Vernacchia, R. A., \& Henschen, K. P. (2008). The challenge of consulting with track and field athletes at the Olympic Games. International Journal of Sport \& Exercise Psychology, 6, 254-266. doi:10.1080/1612197X.2008.9671870

677 Woodman, T. T., \& Hardy, L. L. (2001). A case study of organizational stress in elite sport. 

Journal of Applied Sport Psychology, 13, 207-238. doi:10.1080/104132001753149892

679 Wylleman, P., Harwood, C., Elbe, A-M., Reints, A., \& de Caluwé, D. (2009). A perspective 680 on education and professional development in applied sport psychology. Psychology of 681 Sport and Exercise, 10, 435-446. doi:10.1016/j.psychsport.2009.03.008

682 
684 Figure 1. Number and percentages of intervention issues raised in the sport psychology 685 services in Beijing 2008 and Vancouver 2010 for raw themes, categorised higher order 686 themes and categorised first-order dimensions. Raw data themes with no entry ("high coach 687 expectations"; “nervousness"; "sleep onset and sleep maintenance difficulties";

688 "controversies regarding best training"; "lack of familiarity with competition venues";

689 "climatic conditions" and "nutritional issues") have been omitted in the figure. - indicate no 690 entry in the respective Games. 